\title{
Comparison of the effects of albumin and crystalloid on mortality among patients with septic shock: systematic review with meta-analysis and trial sequential analysis
}

\author{
Yan Zou', Ke Ma"', Ji-Bin Xiong'"', Cai-Hua Xi', Xiao-Jun Deng' \\ Department of Emergency Medicine, Shanghai Jiao Tong University Affiliated Sixth People's Hospital, Shanghai, China
}

'MD. Associate Professor, Department of Intensive Care Medicine, Shanghai Jiao Tong University Affiliated Sixth People's Hospital, Shanghai, China.

(Dorcid.org/0000-0002-6129-1329

"MD. Associate Professor, Department of Emergency Medicine, Shanghai Jiao Tong University Affiliated Sixth People's Hospital,

Shanghai, China.

(Dorcid.org/0000-0003-0871-0819

'"MD. Assistant Professor, Department of Hyperbaric Oxygen Therapy, Shanghai Jiao

Tong University Affiliated Sixth People's Hospital, Shanghai, China.

(D)orcid.org/0000-0002-7983-9452

KEY WORDS:

Albumins.

Crystalloid solutions.

Mortality.

Shock, septic.

\begin{abstract}
BACKGROUND: This study aimed to compare the effects on mortality of albumin and crystalloid, used for fluid resuscitation among adult patients with septic shock, through conducting a meta-analysis and trial sequential analysis (TSA).

DESIGN AND SETTING: Meta-analysis and TSA conducted at Shanghai Jiao Tong University Affiliated Sixth People's Hospital, Shanghai, China.

METHODS: Data were collected from several major databases including MEDLINE, EMBASE, Clinical Trials. gov and Cochrane Central Register of Controlled Trials. Studies that compared the effects of albumin therapy versus crystalloid therapy on mortality among adult septic shock patients were eligible for inclusion in the analyses. The study name, year of publication, country of the trial, albumin concentration, type of crystalloid and all reported mortalities at different follow-up endpoints were extracted.

RESULTS: Compared with crystalloid, albumin did not decrease all-cause mortality at the final follow-up. However, in TSA, the required information size was not achieved in all groups, which means that the effect size was not definitive and further RCTs are needed to confirm or deny these findings

CONCLUSIONS: Compared with crystalloid solutions, albumin was unable to decrease all-cause mortality. However, TSA indicated that these results could be false-negative. Additional randomized controlled trials are needed to clarify this discrepancy.
\end{abstract}

\section{INTRODUCTION}

Sepsis is a life-threatening organ dysfunction caused by a disordered response of the body to infection. ${ }^{1}$ Septic shock is a phenomenon relating to sepsis and is a serious disorder involving both the circulatory system and cell metabolism. During septic shock, extremely low blood pressure is observed, and this requires use of a vasoactive drug after adequate volumetric resuscitation has been applied, in order to maintain average blood pressure $\geq 65 \mathrm{mmHg}$ and lactate concentration $\geq 2 \mathrm{mmol} / \mathrm{l}$. Septic shock is the most life-threatening subtype of sepsis, with a mortality rate of $20 \%$ to $45 \% .^{2}$ Fluid resuscitation is a key component of treatments for sepsis and septic shock.

Over the past 30 years, many randomized clinical trials (RCTs) and systematic reviews ${ }^{3-8}$ that evaluated the therapeutic effects of various fluid resuscitation therapies on sepsis concluded that crystalloid and albumin were the most beneficial therapeutic agents, while use of artificial colloid was associated with a higher death rate and with adverse events. However, few RCTs and systematic reviews have compared the therapeutic effects of crystalloid and albumin regarding septic shock. ${ }^{9-13}$ Moreover, the researchers involved in the studies available differed in their conclusions. ${ }^{14-21}$

According to the findings from the Enhanced Recovery after Surgery (ERAS) study, ${ }^{14}$ albumin does not reduce the mortality rate due to septic shock, whereas the findings from another large RCT called ALBIOS (NCT00707122) ${ }^{15}$ concluded that fluid resuscitation using albumin could reduce the mortality rate from septic shock. In 2014, contrary results were reported in a meta-analysis by Patel et al., ${ }^{16}$ which found that there was no difference between the effects from albumin and crystalloid treatment, while another meta-analysis by Xu et al. ${ }^{17}$ reported that albumin treatment had positive results with regard to reducing the mortality rate among adult patients with septic shock.

These studies have shown that it is not yet a foregone conclusion that albumin is superior to crystalloid for reducing the mortality rate in septic shock cases. In 2015, the Lactated Ringer Versus Albumin in Early Sepsis Therapy (RASP) RCT (NCT01337934) ${ }^{18}$ specifically compared 4\% 
albumin and lactated Ringer's solution with crystalloid, regarding the mortality rate among patients with septic shock. They found that resuscitation with $4 \%$ albumin, as compared with lactated Ringer, did not improve the survival rate among patients with septic shock at 30 days.

The previous descriptions show that, to date, no research findings regarding the preferred method for fluid resuscitation in septic shock cases have yet been conclusive. Our team proposed to conduct a meta-analysis focusing on the differences in the effects of albumin and crystalloid on the mortality rate due to septic shock. Moreover, we used the trial sequential analysis (TSA, available at www.ctu.tsa) method to further analyze the results from the meta-analysis. TSA is a newly proposed statistical analysis method that can improve the strength and accuracy of meta-analyses through applying an overall quantity analysis to it.

\section{METHODS}

\section{Search strategy}

This study was not registered. It was conducted in accordance with the guidance from the Cochrane Collaboration. The study findings were reported in accordance with the Preferred Reporting Items for Systematic Reviews and Meta-Analyses (PRISMA). ${ }^{22,23}$

Data were collected from the following databases: MEDLINE, EMBASE and the Cochrane Central Register of Controlled Trials (CENTRAL). The following keywords were used as searching terms: albumin, crystalloid, sepsis, pyemia* ${ }^{*}$, pyohemia* ${ }^{*}$ blood poisoning, mortality and survival, or prognos ${ }^{\star}$ and predict* ${ }^{\star}$. No language restrictions were placed on the search results. An additional search was carried out in Clinical Trials.gov. The date range of our search was defined as until February 27, 2017 (Table 1).

\section{Eligibility criteria}

The following types of studies were eligible for inclusion:

1. RCTs in which fluid resuscitation comparing albumin and crystalloid solution in adult patients with septic shock was studied; and

2. studies in which the mortality rate among patients with septic shock was assessed.

\section{Data extraction}

Two reviewers (YZ and JBX) independently reviewed full-text manuscripts from the trials thus included. Any disagreement between the two reviewers was resolved through discussion or through consultation with a third reviewer (KM). Data extraction included the following: study name, year of publication, country in which the trial was conducted, trial centers, albumin concentration in the trial, type of crystalloid and all-cause mortality reported at different follow-up endpoints (CHX and XJD). The investigators also tried to contact the authors of the studies included to consult with them and clarify their data and concrete methods, when necessary (done by XJD).

\section{Risk of bias of studies included}

The risk of bias of each study was independently assessed through using the Cochrane Risk of Bias (RoB) table, ${ }^{23}$ in the Review Manager (RevMan) software (version 5.3.3; Nordic Cochrane Centre, Cochrane Collaboration, Copenhagen) The RoB table considers six domains:

1. selection bias (relating to sequence generation and allocation concealment);

2. performance bias (blinding of participants and personnel);

3. measurement bias (blinding of outcome assessment);

4. loss-to-follow-up bias (any incompleteness of outcome data);

5. publication bias (freedom from selective reporting); and

6. other bias.

The overall risk of bias of individual studies was classified into the following categories: low risk of bias, unclear risk of bias and high risk of bias. Low risk was defined as a low risk of bias in all domains; an unclear risk was defined as an unclear risk of bias in at least one domain with no domains showing a high risk of bias; and high risk was defined as a high risk of bias in one or more domains. The risk of bias of the studies included is shown in Table 2.

\section{Grading the quality of evidence}

The quality of evidence was assessed by means of the Grading of Recommendations, Assessment, Development and Evaluation (GRADE) methodology. ${ }^{24}$ The quality of evidence was classified as high, moderate, low or very low, based on judgment of the

Table 1. Search strategies used in MEDLINE, Embase and Cochrane databases

\begin{tabular}{|c|c|}
\hline Databases & Search strategy \\
\hline $\begin{array}{l}\text { MEDLINE(via } \\
\text { PubMed) }\end{array}$ & $\begin{array}{l}\text { (((("Sepsis"[Mesh]) OR ((((((sepsis[Title/Abstract]) OR septic [Title/Abstract]) OR Pyemia*[Title/Abstract]) OR Pyohemia* [Title/Abstract]) } \\
\text { OR Pyaemia*[Title/Abstract]) OR Septicemia* [Title/Abstract]) OR Blood Poisoning[Title/Abstract]))) AND (("Albumins”[Mesh]) OR } \\
\text { albumin*[Title/Abstract])) AND (((“Mortality"[Mesh]) OR “Survival”[Mesh]) OR ((((((mortality [Title/Abstract]) OR fatality[Title/Abstract]) } \\
\text { OR survival[Title/Abstract]) OR death[Title/Abstract]) OR prognos*[Title/Abstract]) OR predict*[Title/Abstract])) }\end{array}$ \\
\hline EMBASE & $\begin{array}{l}\text { ('sepsis'/exp OR ( (Sepsis OR septic OR Pyemia* OR Pyohemia* OR Pyaemia* OR Septicemia*OR 'Blood Poisoning'):ab,ti ) ) AND } \\
\text { ('albumin'/exp OR albumin*:ab,ti) AND (((mortality OR fatality OR death OR prognos* OR predict* OR survival) :ab,ti) or 'mortality'/exp) }\end{array}$ \\
\hline $\begin{array}{l}\text { Cochrane Central } \\
\text { Register of } \\
\text { Controlled Trials }\end{array}$ & $\begin{array}{l}\text { ([Sepsis] or (sepsis:ti,ab,kw or sepic:ti,ab,kw or Pyemia*:ti,ab,kw or Pyohemia*:ti,ab,kw or Pyaemia*:ti,ab,kw) or (Septicemia*:ti,ab,kw } \\
\text { or Blood Poisoning:ti,ab,kw)) and ([Albumins] or albumin*: ti,ab, kw ) and ([Mortality] or [Survival] or mortality:ti,ab,kw or } \\
\text { survival:ti,ab,kw or fatality:ti,ab,kw or death:ti,ab,kw or prognos* :ti,ab,kw or predict*:ti,ab,kw) }\end{array}$ \\
\hline
\end{tabular}


outcome of all-cause mortality, with regard to the risk of bias, inconsistency, indirectness, imprecision and other considerations. ${ }^{24}$ GRADE was applied firstly to each comparison of fluid resuscitation using human albumin and secondly to each predefined risk-of-bias subgroup. The summary shown in Table 3 was constructed using GRADE pro (version 3.6).

\section{Statistical analysis}

The outcomes from the trials included were pooled in terms of either relative risk $(\mathrm{RR}$ [risk ratio = relative risk] $)$ for dichotomous outcomes or mean differences for continuous outcomes with 95\% confidence intervals (CIs). All statistical analyses were performed using the RevMan 5.3.3 software and the Trial Sequential Analysis software (version 0.9 beta). A random-effects model (Mantel-Haenszel method) was used in the presence of statistical heterogeneity or if the situation was judged to present potential for clinical heterogeneity. ${ }^{25}$

Findings in which the $95 \%$ CI boundaries of TSA did not include null ( $<1.00$ or $>1.00)$ were considered statistically significant. The risk of type I error was maintained at $5 \%$ with a power of $80 \%$. The anticipated relative risk and the event proportion in the control arm refer to the results from our meta-analysis. Publication bias was evaluated using a funnel plot (Figure 1). Rational sensitivity analysis was not conducted.

\section{RESULTS}

\section{Study identification and selection}

A total of 3,981 records were identified in the initial search, and of these, 466 records were removed as duplicates. The remaining 3,515 records were screened. After an assessment of the titles and abstracts, 3,465 articles were excluded as not relevant to the analyses. A total of 50 studies were identified as potentially eligible for inclusion. After screening the full-text articles, 12 studies that compared albumin with crystalloid solutions among patients with septic shock were found to be eligible for inclusion. Of these, six studies did not meet the first eligibility criterion (i.e. prospective RCTs) and were excluded (Supplementary file). Thus, in the end, only six studies ${ }^{14,15,18-21}$ representing 3,088 patients with septic shock were included in the meta-analysis and TSA (Figure 2, flow chart). The characteristics of the studies included are listed in Table 4.

\section{Characteristics of studies included}

The characteristics of the studies included are shown in Table 4. All-cause mortality at 28 days was explored in four studies. ${ }^{14,18,20,21}$ Ninety-day mortality rates were shown in two trials. ${ }^{15,21}$ Hospital discharge rates were reported in one study. ${ }^{19}$ Volume expansion for fluid resuscitation was done using $20 \%$ albumin in two trials; ${ }^{14,15} 4 \%$ or $5 \%$ albumin in three studies; ${ }^{18-20}$ and both concentrations in one trial. ${ }^{16}$ Normal saline was used as the crystalloid solution in four trials, ${ }^{14,19-21}$ and lactated Ringer's solution was used in one trial. ${ }^{18}$ The remaining trial ${ }^{10}$ included different kinds of crystalloid products. Four trials had a low or unclear risk of bias ${ }^{14,15,18,20}$ and two studies had a high risk of bias. ${ }^{14,16}$

\section{All-cause mortality at different follow-ups after use of albumin, compared with crystalloid}

\section{Meta-analysis}

Compared with crystalloid solutions, human albumin showed no benefit regarding all-cause mortality at the final follow-up (RR: 0.91; 95\% CI: 0.83-1.00; P =0.05; $\mathrm{I}^{2}=0 \%$; Figure 3). Similarly, use of albumin was not found to have decreased 28-day mortality $^{14,18,20,21}$ (RR 0.96; 95\% CI: 0.83-1.11; $\mathrm{I}^{2}=1 \%$ ) or 90-day ${ }^{18,21}$ mortality (RR: 0.89; 95\% CI: 0.79-1.00; $\mathrm{P}=0.06 ; \mathrm{I}^{2}=0 \%$ ) (Figure 4).

\section{TSA}

A diversity-adjusted information size of 4,815 patients was calculated using $\alpha=0.05$ (two-sided), $\beta=0.20$ (power $80 \%$ ), D2 = $0 \%$, an anticipated RR of $10.0 \%$ (Table 3 ) and an event proportion of $39 \%$ in the control arm (Table 3). The cumulative $z$ curve was constructed using a random-effects model. TSA showed that, out of the required sample size of 4,815 patients, a sample size of 3,088 patients was accrued. The cumulative $\mathrm{z}$ curve touched the conventional boundary for benefit but did not cross the trial sequential monitoring boundary for benefit (Figure 5). This outcome indicates that the result was possibly a false negative because the required sample size was not met.

Table 2. Quality evaluation on the studies included

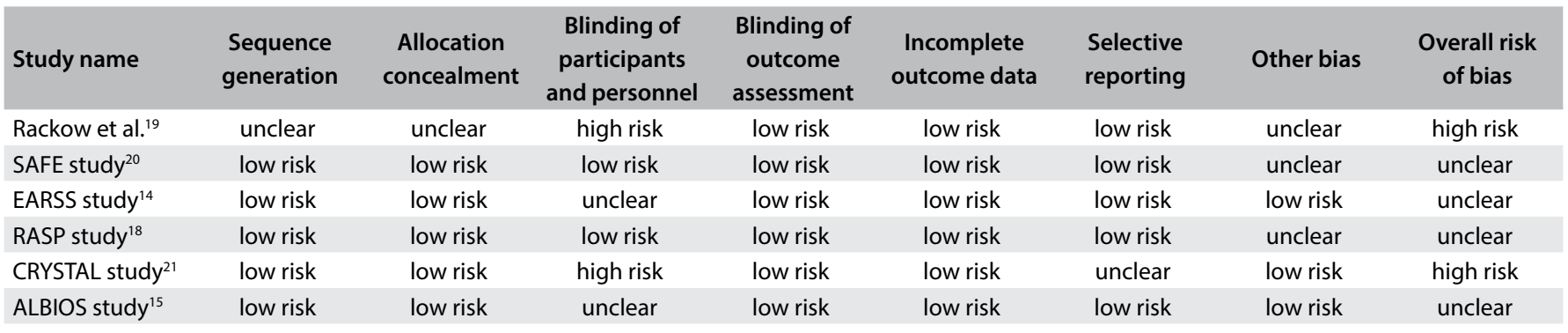







All-cause mortality at final follow-up after use of different concentrations of albumin, compared with crystalloid

\section{Meta-analysis}

Compared with crystalloids, low concentrations of albumin (4\%$5 \%)^{18-20}$ were not found to have reduced all-cause mortality at the final follow-up (RR: 0.96; 95\% CI: 0.78-1.18; P = 0.68; $\mathrm{I}^{2}=8 \%$ ). The high concentration (20\%) albumin subgroups ${ }^{14,21}$ were found to have slightly reduced all-cause mortality (RR: $0.88,95 \% \mathrm{CI}$ : 0.79-0.99, $\mathrm{P}=0.03 ; \mathrm{I}^{2}=0 \%$ ) (Figure 6).

\section{TSA}

A diversity-adjusted information size of 3,177 patients was calculated using $\alpha=0.05$ (two-sided), $\beta=0.20$ (power $80 \%$ ), D2 $=0 \%$, an anticipated RR of $12.0 \%$ (Table 3 ) and an event proportion of $40.2 \%$ in the control arm (Table 3 ). The cumulative $\mathrm{z}$ curve was constructed using a random-effects model. TSA showed that, out of the required 3,177 patient sample size, only a sample size of 1,913 was accrued. The cumulative $\mathrm{z}$ curve touched the conventional boundary for benefit but did not cross the trial sequential monitoring boundary for benefit (Figure 7). This outcome indicates that the result was possibly a false positive because the required sample size was not met.

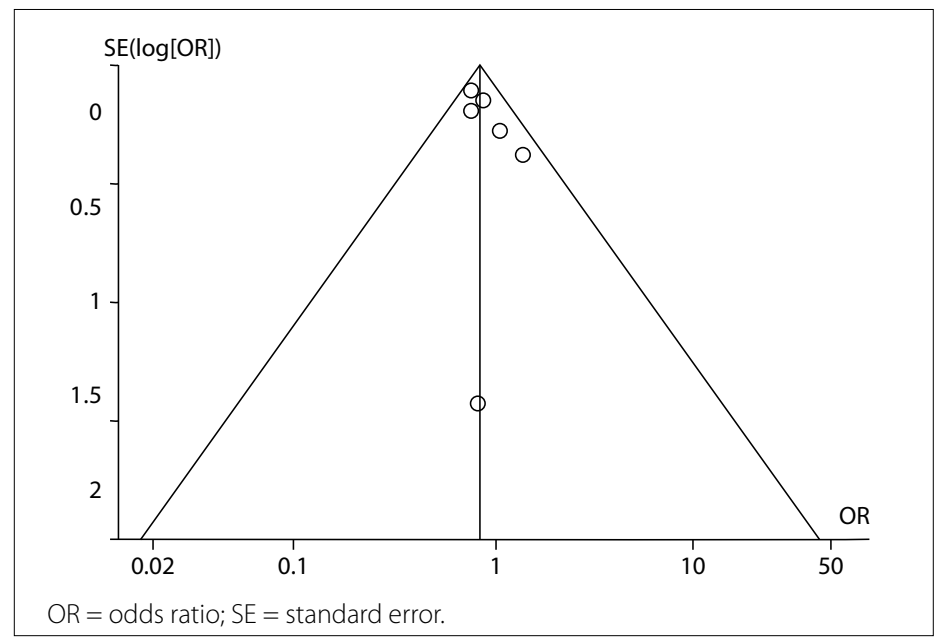

Figure 1. Publication bias was evaluated using a funnel plot.

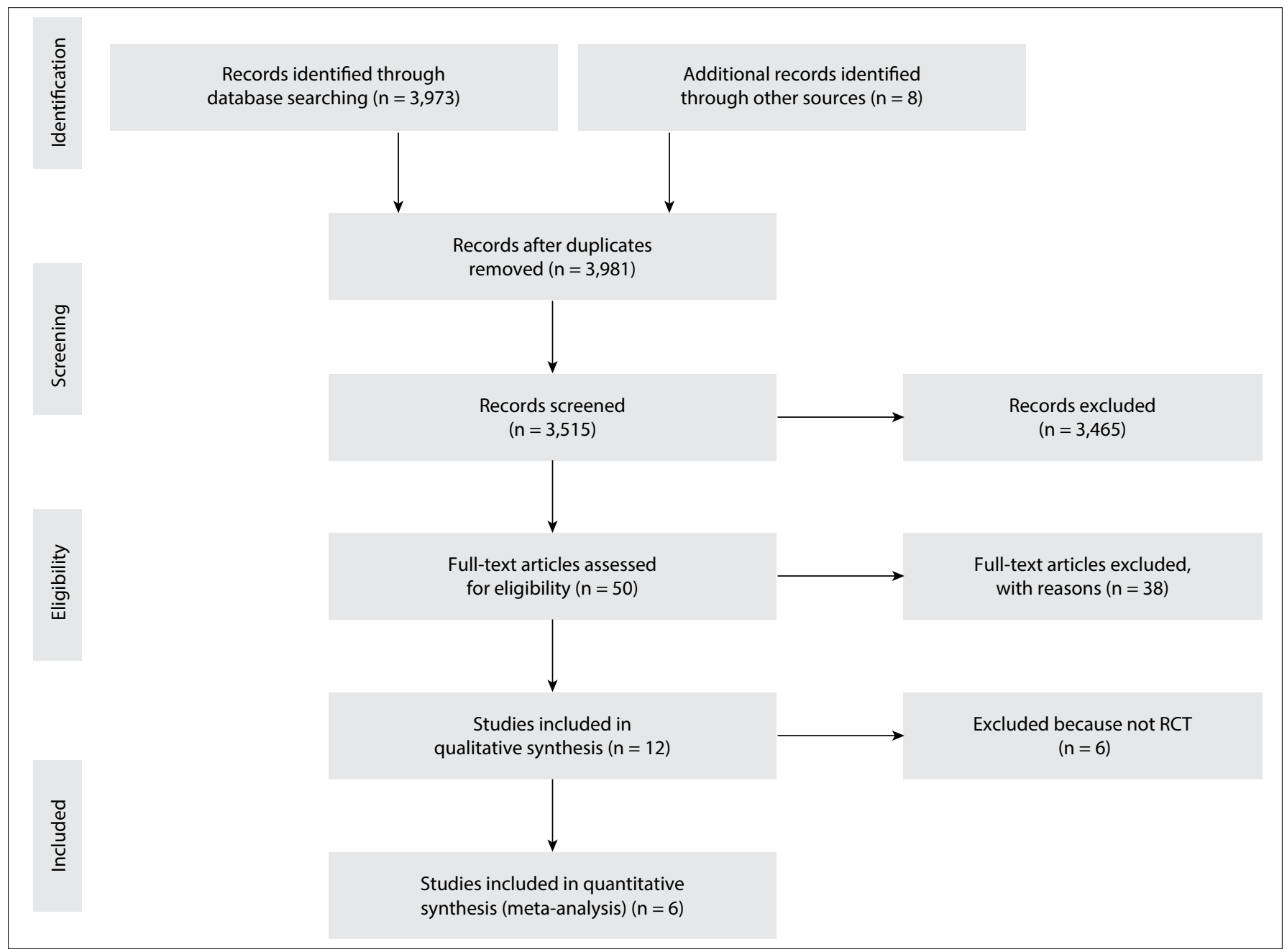

Figure 2. Flow chart of study selection. 
Funnel plots for the comparisons of human albumin with crystalloid showed that there was no publication bias. The odds ratio $(\mathrm{OR})$ and its standard error (SE) are plotted in Figure 1.

\section{DISCUSSION}

The purpose of this research was to compare the effects of albumin and crystalloid solution on the mortality rate among patients with septic shock. Meta-analysis for all-cause mortality showed that albumin offered no benefit in comparison with other interventions for septic shock patients at the final follow-up $(\mathrm{P}=0.05)$. Through the subgroup analysis, significant benefits were observed for the subgroup of $20 \%$ albumin ( $\mathrm{P}=$ $0.03)$. However, after conducting TSA on this meta-analysis we found that these results may not be definitive. Because the required information sizes were not reached, and because the cumulative $\mathrm{z}$ scores did not reach the trial sequential monitoring boundaries of benefit (Figure 5, Figure 7), these results indicated that albumin was not beneficial or harmful in these groups or subgroups. The initial meta-analysis results may have been false negative or positive outcomes. Therefore, additional high-quality RCTs are recommended in order to ensure that correct conclusions are reached. The main difference between the present analysis and previous studies is that, along with inclusion of the most recent RCTs, ${ }^{14,18}$ a TSA was included in the analysis to confirm the results from the initial meta-analysis.

Table 4. Characteristics of studies included

\begin{tabular}{|c|c|c|c|c|c|c|c|c|c|c|c|}
\hline $\begin{array}{l}\text { Study } \\
\text { name }\end{array}$ & Year & Country & Centers & $\begin{array}{c}\text { Albumin } \\
\text { concentration }\end{array}$ & $\begin{array}{c}\text { Type of } \\
\text { crystalloid }\end{array}$ & $\begin{array}{c}\text { 28-day } \\
\text { mortality } \\
\text { (albumin } \\
\text { group) }\end{array}$ & $\begin{array}{l}\text { 28-day } \\
\text { mortality } \\
\text { (crystalloid } \\
\text { group) }\end{array}$ & $\begin{array}{l}\text { 90-day } \\
\text { mortality } \\
\text { (albumin } \\
\text { group) }\end{array}$ & $\begin{array}{c}\text { 90-day } \\
\text { mortality } \\
\text { (crystalloid } \\
\text { group) }\end{array}$ & $\begin{array}{l}\text { Final } \\
\text { follow-up } \\
\text { (albumin } \\
\text { group) }\end{array}$ & $\begin{array}{c}\text { Final } \\
\text { follow-up } \\
\text { (crystalloid } \\
\text { group) }\end{array}$ \\
\hline $\begin{array}{l}\text { Rackow } \\
\text { et al. }{ }^{19}\end{array}$ & 1983 & USA & 1 & $5 \%$ & $\begin{array}{l}\text { Normal } \\
\text { saline }\end{array}$ & $\mathrm{N} / \mathrm{A}^{*}$ & $\mathrm{~N} / \mathrm{A}$ & $\mathrm{N} / \mathrm{A}$ & $\mathrm{N} / \mathrm{A}$ & $5 / 7$ & $3 / 4$ \\
\hline $\begin{array}{l}\text { SAFE } \\
\text { study }^{20}\end{array}$ & $\begin{array}{l}2004 \\
2011\end{array}$ & $\begin{array}{l}\text { Australia and } \\
\text { New Zealand }\end{array}$ & 16 & $4 \%$ & $\begin{array}{l}\text { Normal } \\
\text { saline }\end{array}$ & $70 / 209$ & $90 / 229$ & $\mathrm{~N} / \mathrm{A}$ & $\mathrm{N} / \mathrm{A}$ & $70 / 209$ & $90 / 229$ \\
\hline $\begin{array}{l}\text { EARSS } \\
\text { study }^{14}\end{array}$ & 2011 & France & 29 & $20 \%$ & $\begin{array}{l}\text { Normal } \\
\text { saline }\end{array}$ & $96 / 399$ & $103 / 393$ & $\mathrm{~N} / \mathrm{A}$ & $\mathrm{N} / \mathrm{A}$ & $96 / 399$ & $103 / 393$ \\
\hline $\begin{array}{l}\text { CRYSTAL } \\
\text { study }^{21}\end{array}$ & 2013 & $\begin{array}{c}\text { France, Belgium, } \\
\text { Canada, Algeria } \\
\text { and Tunisia }\end{array}$ & 57 & $5 \%$ or $20 \%$ & $\begin{array}{l}\text { Normal } \\
\text { saline }\end{array}$ & $19 / 59$ & $157 / 557$ & $22 / 59$ & $197 / 557$ & $22 / 59$ & $197 / 557$ \\
\hline $\begin{array}{l}\text { ALBIOS } \\
\text { study }^{15}\end{array}$ & 2014 & Italy & 100 & $20 \%$ & Crystalloid & $\mathrm{N} / \mathrm{A}$ & $\mathrm{N} / \mathrm{A}$ & $243 / 558$ & $281 / 563$ & $243 / 558$ & $281 / 563$ \\
\hline $\begin{array}{l}\text { RASP } \\
\text { study }^{18}\end{array}$ & 2015 & Brazil & 1 & $4 \%$ & $\begin{array}{l}\text { Lactated } \\
\text { Ringer }\end{array}$ & $30 / 50 * *$ & $31 / 60 * *$ & $\mathrm{~N} / \mathrm{A}$ & $\mathrm{N} / \mathrm{A}$ & $30 / 50$ & $31 / 60$ \\
\hline
\end{tabular}

${ }^{*} \mathrm{~N} / \mathrm{A}=$ not applicable; ${ }^{* *}$ we assumed that 30 days was roughly equivalent to 28 days in the RASP study.

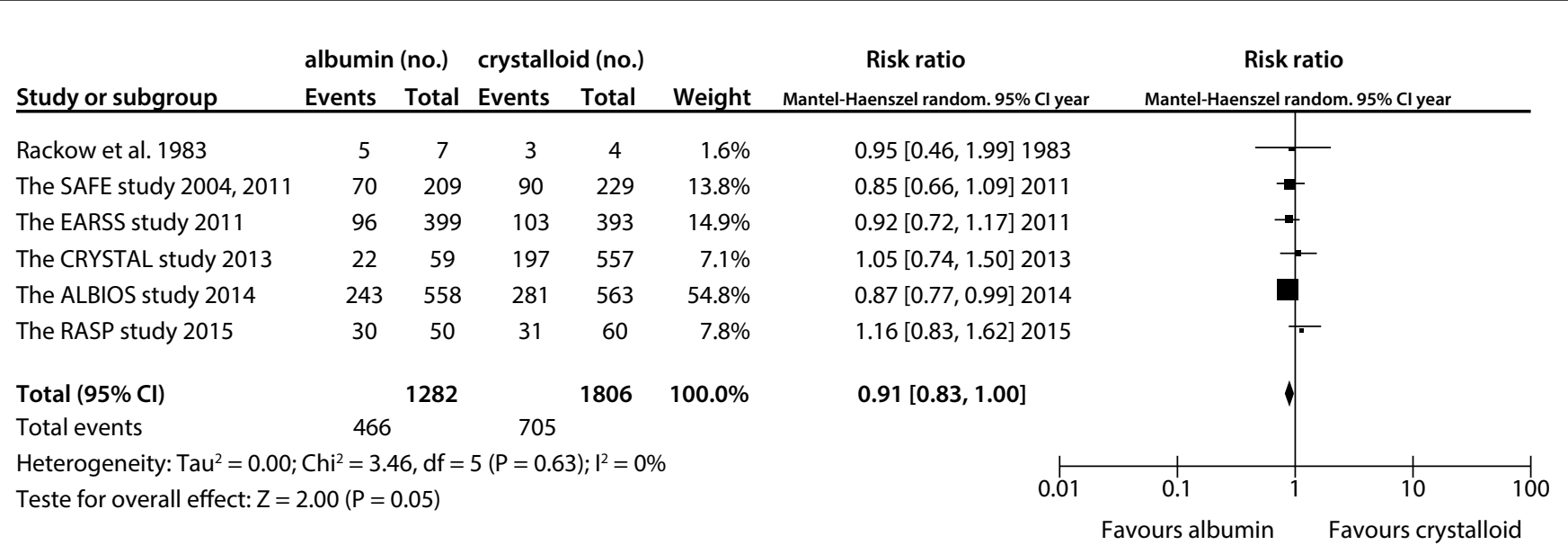

Figure 3. All-cause mortality ascertained at final follow-up, after use of albumin, compared with crystalloid. 
As is well known, sample sizes need to be estimated such that clinical trials are repeatable and sufficient statistical power is ensured. In systematic reviews and meta-analyses, when the number of trials included or the total sample size is too small, the effect will be exaggerated due to random errors. TSA is a newly proposed statistical analysis method that can improve the strength and accuracy of meta-analyses through applying an overall quantity analysis to it. Duplication of a statistically significant experiment would increase the risk of type I error in the hypothesis test, which would mean creation of a false positive. ${ }^{26-29} \mathrm{TSA}^{30}$ involves the principle and method of the trial sequence. Through checking the P-value and its CI, this method has the following significant advantages:

1. the conclusion can be generated earlier without increasing the type I error;

2. the sample size can be estimated; and

3. hints for further research studies are provided through numerical data and visualized sample sizes.
Research studies have shown that $25 \%$ of traditional meta-analyses produced false positive results due to small sample sizes. ${ }^{31}$ With the help of this advanced method, our research was more precise and novel.

From a theoretical point of view, albumin is an ideal resuscitation fluid for treating septic shock, but its use in research studies has not demonstrated it to be superior to other resuscitation fluids. The reason for this discrepancy may have been the insignificant reduction in the mortality rate when albumin was compared with crystalloids and the lack of high-quality RCTs comparing albumin and crystalloid solutions in septic shock cases. In addition, further suggestions were provided for the experimental design of further studies based on the present research. More benefits could be produced through using crystalloid solutions compared with albumin, especially at high albumin concentrations, as well as through well-designed RCTs.

There are other limitations to the present research study. Firstly, a measurable error is generated if a blinded method was not applied in

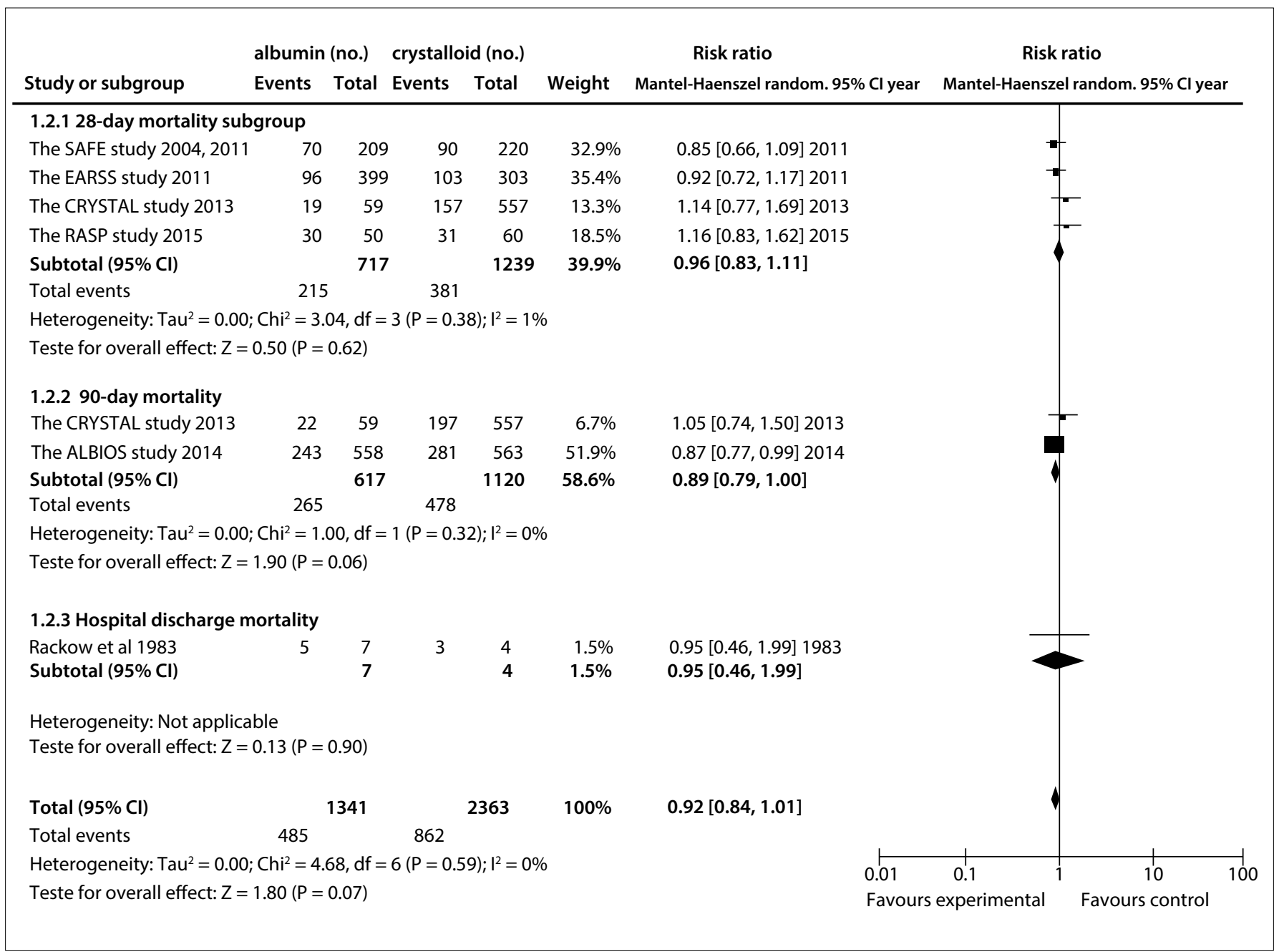

Figure 4. All-cause mortality ascertained at different follow-ups, after use of albumin, compared with crystalloid. 
the studies, and therefore it is recommended that a blinded method should be used in future research studies for better quality. Secondly, although statistical heterogeneity between studies was not found, clinical and methodological heterogeneity may have been present. Thirdly, different follow-up durations were used, and different follow-up durations would obviously have different results. Fourthly, TSA had limitations, given that it was unable to resolve the error that was generated by the quality of the initial search methodology and by the uncertainty from the result. In addition, the initial search would have affected the TSA output if its quality was low.

Although TSA showed that there was a possibility that, without inclusion of further RCTs to provide additional support, the results from the meta-analysis could have been false positives, the output from the meta-analysis was still useful as guidance for experimental designs and field applications in the future. As the results showed, there is a high possibility that a high concentration of albumin can produce a positive result regarding decreased mortality, when used for fluid resuscitation in cases of septic shock. In short, TSA should be strongly recommended and should be more used for future review studies, so that evidence of greater reliability and consistency can be obtained.

PRECISE (NCT0019416) ${ }^{9}$ has been completed. This is another large-scale RCT that focuses on comparing the effects of albumin

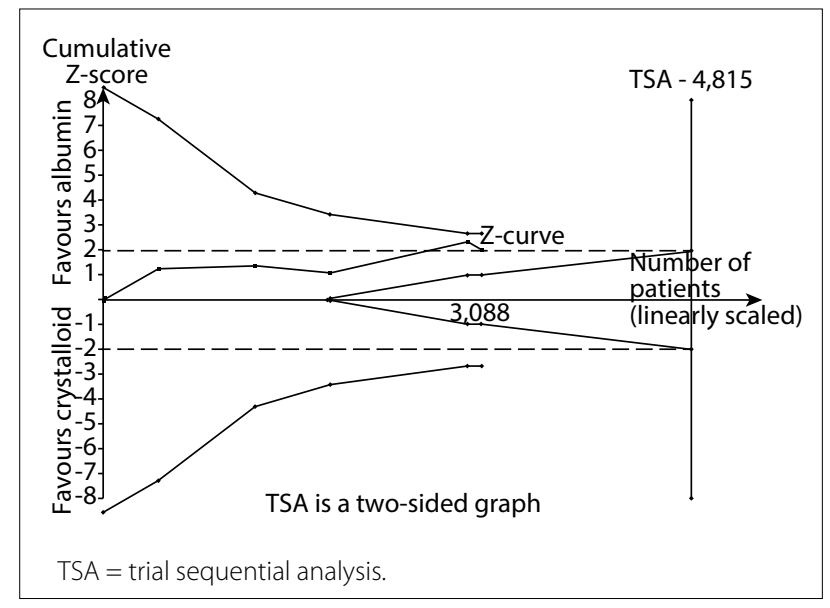

Figure 5. A diversity-adjusted information size of 4,815 patients was calculated using $\alpha=0.05$ (two-sided), $\beta=0.20$ (power $80 \%$ ), D2 $=0 \%$, an anticipated relative risk of $10.0 \%$ (refer to our meta-analysis) and an event proportion of $39 \%$ in the control arm (refer to our meta-analysis). The cumulative $z$ curve was constructed using a random-effects model. Trial sequential analysis showed that 3,088 patients out of the required information size of 4,815 patients were accrued. The cumulative $z$ curve touched the conventional boundary for benefit but did not cross the trial sequential monitoring boundary for benefit.

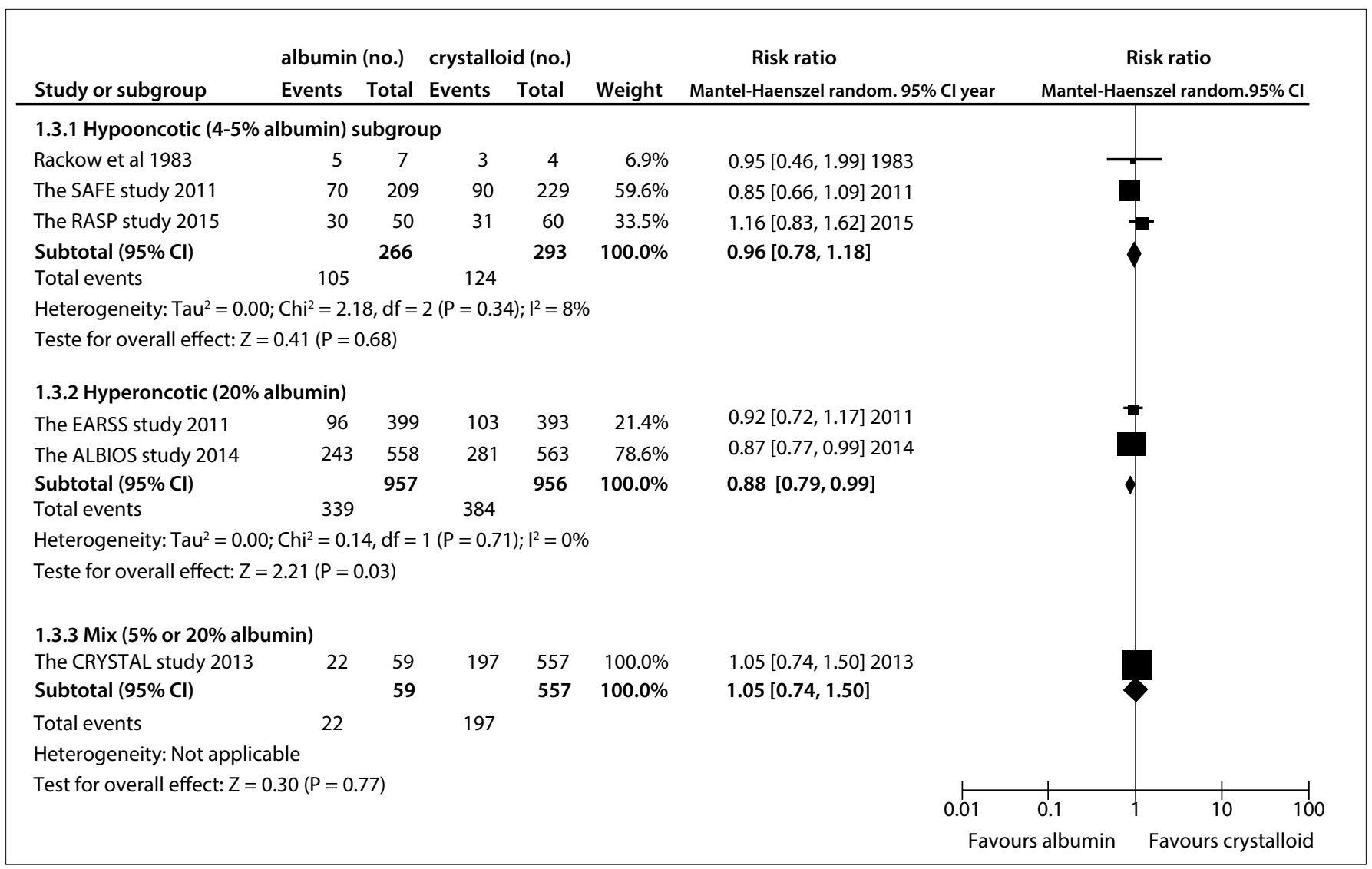

Figure 6. All-cause mortality ascertained at final follow-up, after use of different albumin concentrations, compared with crystalloid. 


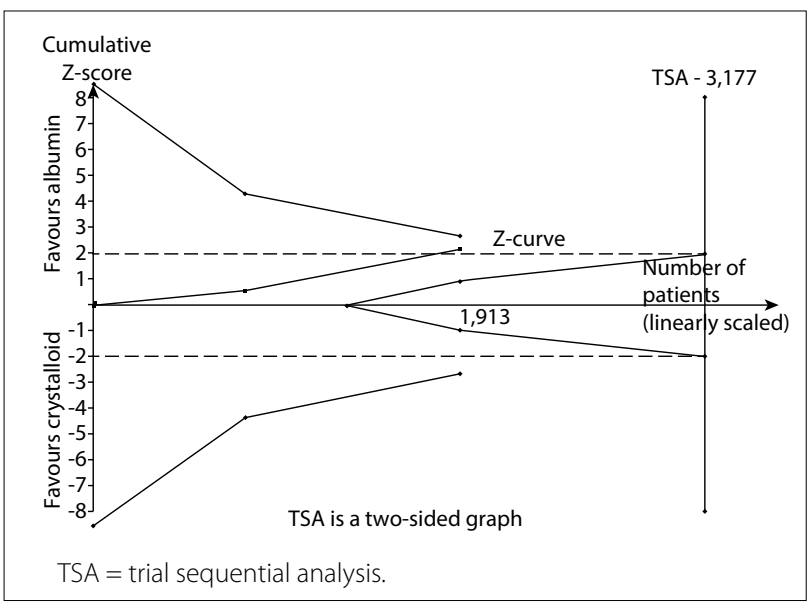

Figure 7. A diversity-adjusted information size of 3,177 patients was calculated using $\alpha=0.05$ (two-sided), $\beta=0.20$ (power $80 \%$ ), D2 $=0 \%$, an anticipated relative risk of $12.0 \%$ (refer to our meta-analysis) and an event proportion of $40.2 \%$ in the control arm (refer to our meta-analysis). The cumulative $z$ curve was constructed using a random-effects model. Trial sequential analysis showed that 1,913 patients out of the required information size of 3,177 patients were accrued. The cumulative $z$ curve touched the conventional boundary for benefit but did not cross the trial sequential monitoring boundary for benefit.

and normal saline on the mortality rate due to septic shock. The conclusion of this RCT is eagerly awaited, given that the sample size of the meta-analysis will reach the required information size. Thus, it will help determine whether the reduction in mortality that is associated with use of albumin is a truly positive result or a type I error.

\section{CONCLUSIONS}

The results from the meta-analysis showed that, in comparison with use of crystalloid, human albumin did not decrease all-cause mortality, as evaluated at the final follow-up. The trial sequential analysis results suggest that the negative results observed so far might not be definitive. Further RCTs are needed to confirm this result.

\section{REFERENCES}

1. Singer M, Deutschman CS, Seymour CW, et al. The Third International Consensus Definitions for Sepsis and Septic Shock (Sepsis-3). JAMA. 2016;315(8):801-10. PMID: 26903338; doi: 10.1001/jama.2016.0287.

2. Asfar P, Meziani F, Hamel JF, et al. High versus low blood-pressure target in patients with septic shock. N Engl J Med. 2014;370(17):1583-93. PMID: 24635770; doi: 10.1056/NEJMoa1312173.

3. Angus DC, van der PollT. Severe sepsis and septic shock. N Engl J Med. 2013;369(9):840-51. PMID: 23984731; doi: 10.1056/NEJMra1208623.

4. Ospina-Tascon G, Neves AP, Occhipinti G, et al. Effects of fluids on microvascular perfusion in patients with severe sepsis. Intensive Care Med. 2010;36(6):949-55. PMID:20221744; doi: 10.1007/s00134-010-1843-3.
5. Niemi TT, Miyashita R, Yamakage M. Colloid solutions: a clinical update. Anesth. 2010;24(6):913-25.PMID:20953964; doi: 10.1007/s00540-010-1034-y.

6. Myburgh JA, Finfer S, Bellomo R, et al. Hydroxyethyl starch or saline for fluid resuscitation in intensive care. N Engl J Med. 2012;367(20):1901-11. PMID: 23075127; doi: 10.1056/NEJMoa1209759.

7. Guidet B, Martinet $O$, Boulain T, et al. Assessment of hemodynamic efficacy and safety of $6 \%$ hydroxyethyl starch $130 / 0.4$ vs. $0.9 \% \mathrm{NaCl}$ fluid replacement in patients with severe sepsis: the CRYSTMAS study. Crit Care. 2012;16(3):R94. PMID: 22624531; doi: 10.1186/cc11358.

8. Perner A, Haase N, Guttormsen AB, et al. Hydroxyethyl starch 130/0.42 versus Ringer's acetate in severe sepsis. N Engl J Med. 2012;367(2):12434. PMID: 22738085; doi: 10.1056/NEJMoa1204242.

9. McIntyre L, Fergusson DA, Rowe B, et al. The PRECISE RCT: evolution of an early septic shock fluid resuscitation trial. Transfus Med Rev. 2012;26(4): 333-41. PMID: 22222146; doi: 10.1016/j.tmrv.2011.11.003.

10. Zhong JZ, Wei D, Pan HF, et al. Colloid solutions for fluid resuscitation in patients with sepsis: systematic review of randomized controlled trials. J Emerg Med. 2013;45(4):485-95. PMID: 23932700; doi: 10.1016/j. jemermed.2013.05.018.

11. Jiang $L$, Jiang S, Zhang M, Zheng Z, Ma Y. Albumin versus other fluids for fluid resuscitation in patients with sepsis: a meta-analysis. PLOS One. 2014;9(12):e114666. PMID: 25474401; doi: 10.1371/journal. pone.0114666

12. $M a P L$, Peng $X X, D u B$, et al. Sources of heterogeneity in trials reporting hydroxyethyl starch 130/0.4 or 0.42 associated excess mortality in septic patients: A systematic review and meta-regression. Chin Med J (Engl). 2015;128(17):2374-82. PMID: 26315087; doi: 10.4103/0366-6999.163387.

13. Raghunathan K, Bonavia A, Nathanson BH, et al. Association between initial fluid choice and subsequent in-hospital mortality during the resuscitation of adults with septic shock. Anesthesiology. 2015; 123(6): 1385-93. PMID: 26414499; doi: 10.1097 /ALN. 0000000000000861.

14. Charpentier J, Mira JP, EARSS Study Group. Efficacy and tolerance of hyperoncotic albumin administration in septic shock patients: the EARSS study (Abstract). Intensive Care Med. 2011; 37(Suppl1):S115.

15. Caironi $P$, Tognoni $G$, Masson S, et al. Albumin replacement in patients with severe sepsis or septic shock. N Engl J Med. 2014;370(15):1412-21. PMID: 24635772; doi: 10.1056/NEJMoa1305727.

16. Patel A, Laffan MA, Waheed U, Brett SJ. Randomised trials of human albumin for adults with sepsis: systematic review and meta-analysis with trial sequential analysis of all-cause mortality. BMJ. 2014;349:g4561 . PMID: 25099709; doi: 10.1136/bmj.g4561

17. Xu JY, Chen $Q H$, Xie JF, et al. Comparison of the effects of albumin and crystalloid on mortality in adult patients with severe sepsis and septic shock: a meta-analysis of randomized clinical trials. Crit Care. 2014;18(6):702. PMID: 25499187; doi: 10.1186/s13054014-0702-y.

18. Park C, Osawa E, Almeida J, et al. Lactated Ringer Versus Albumin in Early Sepsis Therapy (RASP) study: preliminary data of a randomized controlled trial. Crit Care. 2015;19(Suppl 1):P355. doi:10.1186/cc14435. 
19. Rackow EC, Falk JL, Fein IA, et al. Fluid resuscitation in circulatory shock: a comparison of the cardiorespiratory effects of albumin, hetastarch, and saline solutions in patients with hypovolemic and septic shock. Crit Care Med. 1983;11(11):839-50. PMID: 6194934.

20. Finfer $S$, Bellomo R, Boyce $N$, et al. A comparison of albumin and saline for fluid resuscitation in the intensive care unit. N Engl J Med. 2004;350(22):2247-56. PMID: 15163774; doi: 10.1056/NEJMoa040232.

21. Annane D, Siami S, Jaber S, et al. Effects of fluid resuscitation with colloids vs crystalloids on mortality in critically ill patients presenting with hypovolemic shock: the CRISTAL randomized trial. JAMA. 2013;310(17):1809-17. PMID:24108515; doi: 10.1001/jama.2013.280502.

22. Moher D, Liberati A, TetzlaffJ, Altman DG, PRISMA Group. Preferred reporting items for systematic reviews and meta-analyses: the PRISMA statement. Int J Surg. 2010;8(5):336-41. PMID: 20171303; doi: 10.1016/j.jisu.2010.02.007.

23. Higgins JP, Green S. Cochrane Handbook for Systematic Reviews of Interventions version 5.1.0 [updated March 2011]. Cochrane Collaborations; 2011. Available from: http://handbook-5-1.cochrane. org/. Accessed in 2018 (Jan 3).

24. Guyatt GH, Oxman AD, Vist GE, et al. GRADE Working Group. GRADE: an emerging consensus on rating quality of evidence and strength of recommendations. BMJ. 2008;336(7650):924-6. PMID: 18436948; doi: 10.1136/bmj.39489.470347.AD.

25. Borenstein $M$, Hedges LV, Higgins JPT, Rothstein HR. Introduction to Meta-analysis. In: Borenstein M, Hedges LV, Higgins JPT, Rothstein HR, editors. Part 3: Fixed-effect versus random-effect models. West Sussex: John Wiley \& Sons; 2009. p. 61-102. ISBN: 978-0-470-05724-7.

26. Wang JY, Xiao L, Chen J, et al. Potential effectiveness of traditional Chinese medicine for cardiac syndrome X (CSX): a systematic review and meta-analysis. BMC Complement Altern Med. 2013;13:62. PMID: 23497135; doi: 10.1186/1472-6882-13-62.

27. Wang HF, Yu JT, Tang SW, et al. Efficacy and safety of cholinesterase inhibitors and memantine in cognitive impairment in Parkinson's disease, Parkinson's disease dementia, and dementia with Lewy bodies: systematic review with meta-analysis and trial sequential analysis. J Neurol Neurosurg Psychiatry. 2015;86(2):135-43. PMID: 24828899; doi: 10.1136/jnnp-2014-307659.

28. Thorlund K, Engstr OM, Wetterslev J, et al. User manual for trial sequential analysis (TSA). Copenhagen Trial Unit, Centre for Clinical Intervention Research; 2017. Available from http://www.ctu.dk/tsa/files/tsa_manual. pdf. Accessed in 2018 (Mar 9).

29. Higgins JPT, Green S. Cochrane handbook for systematic reviews of interventions. Chichester:Wiley-Blackwell; 2008. ISBN: 978-0-470-69951-5.

30. Wetterslev J, Thorlund K, Brok J, Gluud C. Trial sequential analysis may establish when firm evidence is reached in cumulative meta-analysis. J Clin Epidemiol. 2008;61(1):64-75. PMID: 18083463; doi: 10.1016/j. jclinepi.2007.03.013.

31. Thorlund K, Devereaux PJ, Wetterslev J, et al. Can trial sequential monitoring boundaries reduce spurious inferences from meta-analyses? Int J Epidemiol. 2009;38(1):276-86. PMID: 18824467; doi: 10.1093/ije/dyn179.
Acknowledgements: The authors thank all authors whose publications could be included in our meta-analysis

Sources of funding: There are no funders to report for this study Conflict of interest: None

Date of first submission: July 23, 2017

Last received: October 10, 2017

Accepted: October 28, 2017

\section{Address for correspondence:}

Ke Ma

Department of Emergency Medicine, Shanghai Jiao Tong University Affiliated Sixth People's Hospital East Campus,

No. 222 Huanhuxisan Road,

Shanghai 201306 - China

Tel. +8618930177703

Fax. +862138297733

E-mail:dockema@163.com 
Supplementary file.

Studies excluded and reasons for this.

\begin{tabular}{|c|c|c|}
\hline First author & Subject & Reason for exclusion \\
\hline Dahn $1979^{1}$ & Negative inotropic effect of albumin resuscitation for shock. & $\begin{array}{l}\text { Seriously injured patients were included in the study, and data on } \\
\text { severe sepsis were inadequate. }\end{array}$ \\
\hline Lucas $1979^{2}$ & $\begin{array}{l}\text { Impaired salt and water excretion after albumin resuscitation for } \\
\text { hypovolemic shock. }\end{array}$ & $\begin{array}{l}\text { Hypovolemic shock patients were included in the study, and data } \\
\text { on severe sepsis were inadequate. }\end{array}$ \\
\hline Lucas $1980^{3}$ & $\begin{array}{l}\text { Impaired pulmonary function after albumin resuscitation } \\
\text { from shock. }\end{array}$ & $\begin{array}{l}\text { Shock patients were included in the study, and data on severe } \\
\text { sepsis were inadequate. }\end{array}$ \\
\hline Foley $1990^{5}$ & Albumin supplementation in critically ill patients. & included in the study, and data \\
\hline Younes $1992^{6}$ & $\begin{array}{l}\text { Hypertonic solutions for treating hypovolemic shock: a } \\
\text { prospective, randomized study on patients admitted to the } \\
\text { emergency room. }\end{array}$ & $\begin{array}{l}\text { Hypovolemic shock patients were included in the study, and data } \\
\text { on severe sepsis were inadequate. }\end{array}$ \\
\hline $\begin{array}{l}\text { Stockwell } \\
1992^{7}\end{array}$ & $\begin{array}{l}\text { Colloid solutions in critically ill patients: a randomized comparison } \\
\text { of albumin and polygeline. Outcome and duration of stay in the } \\
\text { intensive care unit. }\end{array}$ & $\begin{array}{l}\text { All patients were included in the study, and data on severe sepsis } \\
\text { were inadequate. }\end{array}$ \\
\hline Golub $1994^{9}$ & $\begin{array}{l}\text { Efficacy of albumin supplementation in surgical intensive care } \\
\text { unit: a prospective, randomized study. }\end{array}$ & $\begin{array}{l}\text { The study was conducted in the surgical intensive care unit, and } \\
\text { data on severe sepsis were inadequate. }\end{array}$ \\
\hline Steltzer $1994^{10}$ & $\begin{array}{l}\text { Hemodynamic evaluation during small-volume resuscitation } \\
\text { among patients with acute respiratory failure. }\end{array}$ & $\begin{array}{l}\text { Acute respiratory failure patients were included in the study, and } \\
\text { data on severe sepsis were inadequate. }\end{array}$ \\
\hline Boldt $1996^{11}$ & $\begin{array}{l}\text { Effects of albumin versus hydroxyethyl starch solution on cardio } \\
\text { respiratory and circulatory variables in critically ill patients. }\end{array}$ & $\begin{array}{l}\text { Comparison was between albumin and low-molecular weight } \\
\text { hydroxyethyl starch solution, not between albumin and crystalloid. }\end{array}$ \\
\hline Rock $1997^{12}$ & $\begin{array}{l}\text { Pentastarch instead of albumin as replacement fluid for } \\
\text { therapeutic plasma exchange. }\end{array}$ & $\begin{array}{l}\text { Comparison was between albumin and pentastarch, not between } \\
\text { albumin and crystalloid. }\end{array}$ \\
\hline Rubin $1997^{13}$ & $\begin{array}{l}\text { Randomized, double blind study on intravenous human albumin } \\
\text { in hypoalbuminemic patients receiving total parenteral nutrition. }\end{array}$ & $\begin{array}{l}\text { Hypoalbuminemic patients were included in the study, and data } \\
\text { on severe sepsis were inadequate. }\end{array}$ \\
\hline
\end{tabular}
Hemodynamic response of modified fluid gelatin compared with Wu $2001^{15} \quad$ lactated Ringer's solution for volume expansion in emergency resuscitation of hypovolemic shock patients: preliminary report on a prospective, randomized trial.

Oliveira $2002^{16}$ Acute hemodynamic effects of a hypertonic saline/dextran solution in stable patients with severe sepsis.

Quinlan 2004 Albumin influenced total plasma antioxidant capacity favorably in patients with acute lung injury.

Veneman Human albumin and starch administration in critically ill patients: $2004^{18} \quad$ a prospective randomized clinical trial.

Vincent $2005^{19}$ Albumin administration in acutely ill patients in relation to increased mortality :results from the SOAP study.

Palumbo $2006^{20}$

Dubois $2006^{12}$ Effects of hydroxyethyl starch solution on critically ill patients.

Albumin administration improved organ function in critically ill hypoalbuminemic patients: a prospective, randomized, controlled, pilot study.

Bellomo Effects of saline or albumin resuscitation on acid-base status and $2006^{22} \quad$ serum electrolytes.

McIntyre Resuscitating patients with early severe sepsis: a Canadian

$2007^{23}$

Guidet $2007^{24}$ multicenter observational study.

The COASST study: cost-effectiveness of albumin in cases of severe sepsis and septic shock.

McIntyre Fluid resuscitation in management of early septic shock (FINESS): $2008^{25}$ a randomized controlled feasibility trial.
Hypovolemic shock patients were included in the study, and data on severe sepsis were inadequate.

Comparison was between hypertonic saline/dextran solution and saline, not between albumin and crystalloid.

Acute lung injury patients were included in the study, and data on severe sepsis were inadequate.

Severe sepsis patients were included in the study, and the mortality data on the albumin group and crystalloid group were inadequate.

Not a randomized controlled or parallel clinical trial.

Comparison was between albumin and hydroxyethyl starch, not between albumin and crystalloid.

Hypoalbuminemic patients were included in the study, and data on severe sepsis were inadequate.

Not a randomized controlled or parallel clinical trial.

Not a randomized controlled or parallel clinical trial.

Not a randomized controlled or parallel clinical trial.

Comparison was between pentastarch and saline, not between albumin and crystalloid. 


\section{Supplementary file.}

Studies excluded and reasons for this (continuation).



Scandinavian

Critical Care

Trials Group

$2011^{35}$

McIntyre

$2012^{36}$

van Haren

$2012^{37}$

Myburgh

$2012^{38}$

Yunos $2012^{39}$

McIntyre

$2012^{40}$

Perez $2013^{41}$

Masson $2014^{42}$

Caironi $2015^{43}$

Chang $2016^{44}$
Comparing the effect of hydroxyethyl starch 130/0.4 with balanced crystalloid solution on mortality and kidney failure in patients with severe sepsis (6S: Scandinavian Starch for Severe Sepsis/Septic Shock trial): study protocol, design and rationale for a double-blinded, randomized clinical trial.

Fluid resuscitation with $5 \%$ albumin versus normal saline in early septic shock: a pilot randomized, controlled trial.

Hypertonic fluid administration in patients with septic shock: a prospective randomized controlled pilot study.

Hydroxyethyl starch or saline for fluid resuscitation in intensive care.

Association between a chloride-liberal vs chloride-restrictive intravenous fluid administration strategy and kidney injury in critically ill adults.

The PRECISE RCT: evolution of an early septic shock fluid resuscitation trial.

Intravenous $0.9 \%$ sodium chloride therapy did not reduce length of stay of alcohol-intoxicated patients in the emergency department: a randomized controlled trial.

Presepsin (soluble CD14 subtype) and procalciton in levels for mortality prediction in sepsis: data from the Albumin Italian Outcome Sepsis trial.

Albumin in critically ill patients: the ideal colloid?

Choice of fluid therapy in the initial management of sepsis, severe sepsis, and septic shock.
Comparison was between crystalloid and hydroxyethyl starch, not between albumin and crystalloid.

Septic shock patients were included in the study, and the mortality data on the albumin group and saline group were inadequate.

Comparison was between hypertonic fluid and isotonic fluid, not between albumin and crystalloid.

Comparison was between hydroxyethyl starch and saline, not between albumin and crystalloid.

\section{Not a randomized controlled or parallel clinical trial}

Septic shock patients were included in the study, and the mortality data on the albumin group and saline group were inadequate. Acute alcohol intoxication patients were included in the study; the mortality data on the albumin group and saline group were inadequate; and the comparison was not between albumin and crystalloid.

Comparison was not between albumin and crystalloid.

Not a controlled or parallel clinical trial.

Choice of fluid therapy in the initial management of sepsis, severe sepsis, and septic shock. 